\title{
A GESTÃO DO CONHECIMENTO NO SERVIÇO AEROMÉDICO
}

\author{
Bruno Gonçalves da Silva ${ }^{1}$, Thais Campos Maria² ${ }^{2}$ Flávio Lopes Ferreira ${ }^{3}$, Fabrício \\ Ziviani $^{4}$
}

\section{RESUMO}

O transporte aeromédico teve início como uma modalidade de resgate aéreo de soldados feridos, desde a Guerra Franco-Prussiana, por meio de balões. Com o desenvolvimento bélico, a medicina de guerra teve que se adaptar e evoluir em parâmetros de adequação à equação gravidade e necessidade de transporte imediato para longas distâncias em curto prazo de tempo. Essa modalidade de transporte de pacientes criticamente enfermos se estendeu para a população civil. Atualmente, conta com equipe médica composta por médicos e enfermeiros capacitados e com experiência em atendimento pré-hospitalar, de urgência e emergência, além de tais profissionais terem a necessidade de constante atualização e de um processo sistemático de educação continuada ou permanente. O presente trabalho visa apresentar a necessidade da Gestão do Conhecimento na capacitação da equipe médica em um serviço de transporte aeromédico. A justificativa se baseia na Portaria no1863 de 2003 do Ministério da Saúde, que regulamenta a educação continuada da equipe de atendimento à urgência. Esse trabalho justifica-se pela necessidade de compreender a influência da Gestão do Conhecimento para que haja essa capacitação. Este estudo trata de uma revisão de literatura referente à gestão do conhecimento nos serviços de transporte aeromédicos. O resultado esperado é a garantia da prática de atividades baseadas nas referências técnicas-científicas.

Palavras-chaves: Gestão do Conhecimento, resgate aeromédico, capacitação.

\section{INTRODUÇÃO}

O transporte aeromédico é uma modalidade de transporte que se destina a pacientes gravemente enfermos e que necessitam de uma remoção para uma unidade de atendimento médico especializado e num período de tempo curto (HERNÁNDEZ, OLIVERA, 2007).

\footnotetext{
1. Enfermeiro de bordo da Unimed Aeromédica. Doutorando Tecnologia da Informação e Gestão do Conhecimento, pela FUMEC - BH. Docente da Faculdade de Ciências Médicas de Minas Gerais. Especialista em Terapia Intensiva, pediátrica, neonatal e adulto. E-mail: brunoenf87@gmail.com

2. Servidora do IFMG - Campus Congonhas, MG - Brasil. Doutoranda em Sistemas de Informação e Gestão do Conhecimento pela Universidade Fundação Mineira de Educação e Cultura (FUMEC) - Belo Horizonte, MG - Brasil. E-mail: tahcampos@hotmail.com

3.Gestor médico da Unimed Aeromédica, Mestre e Doutorando em Ciências Biológicas com Área de Concentração em Farmacologia e fisiologia, Docente da Faculdade de Ciências Médicas de Minas Gerais. E-mail: flopes@unimedaeromédica.com.br 4. Professor Adjunto Universidade FUMEC e Universidade Estadual de Minas Gerais (UEMG). Doutor em Sistemas da Informação pela Universidade Federal de Minas Gerais (UFMG). Email: contato@fabricioziviani.com.br
} 
Os primeiros transportes aeromédicos datam de 1870, feitos durante a Guerra Franco-Prussiana, quando soldados feridos em campo de batalha eram aerorremovidos por meio de balões de ar quente. No entanto, foi na Primeira Guerra Mundial que houve o marco histórico na utilização do transporte aéreo e na Segunda Guerra Mundial foi oficialmente descrita a participação da enfermagem no processo de cuidado durante voo. Desde então, a medicina de guerra desenvolveu vários recursos que foram aplicados a soldados e trazidos para civis até os dias atuais (GENTIL, 1997; GOMES, 2013).

Com base na Portaria nº1863 de 2003 do Ministério da Saúde, que regulamenta a educação continuada da equipe de atendimento à urgência, este trabalho justifica-se pela necessidade de compreender a influência da Gestão do Conhecimento para que haja essa capacitação. O objetivo é apresentar a necessidade da Gestão do Conhecimento na capacitação da equipe médica em um serviço de transporte aeromédico.

\section{METODOLOGIA}

Este estudo apresenta uma revisão de literatura referente à gestão do conhecimento nos serviços de transporte aeromédicos. A busca bibliográfica foi realizada no período compreendido entre julho e agosto de 2019. As bases de dados escolhidas por este estudo foram as seguintes: BVS (Biblioteca Virtual em Saúde) e Scielo. Para a busca dos artigos científicos, utilizaram-se as seguintes palavraschaves: "resgate aeromédico" E "gestão do conhecimento" E "capacitação" em cada uma das bases de dados citadas. Os critérios de inclusão foram (i) artigos publicados nos últimos dez anos, (ii) artigos publicados nos idiomas português e inglês. Outros artigos foram identificados a partir das listas de referências bibliográficas citadas nos artigos selecionados neste estudo.

\section{RESULTADOS E DISCUSSÕES}

No que tange à legislação brasileira, o transporte aeromédico deve estar sob autoridade técnica de um diretor médico com habilitação e capacitação em emergência pré-hospitalar, com noções básicas de Fisiologia de voo e de regulamentação aeronáutica. Pode-se dizer que é recomendado que o gestor 
possua habilitação em Medicina Aeroespacial. Dessa forma, toda empresa que presta o serviço aeromédico deve ter seu cadastro devidamente registrado no Conselho Regional de Medicina (CRM) de sua região. Tal definição está prevista na Resolução do Conselho Federal de Medicina (CFM) n 1596 de nove de junho de 2000, que foi atualizada pela Resolução CFM 1661 de 2003 (CFM, 2003).

O Conselho Federal de Enfermagem regulamenta a atuação do enfermeiro como especialista, pela Resolução do Conselho Federal de Enfermagem (COFEN) no 260/2001, que pode atuar em várias áreas tais como enfermeiro em préhospitalar, neonatologia, terapia intensiva e aeroespacial (COFEN, 2001).

Como mencionado acima, o profissional de saúde deve ter capacitação para realização do transporte aeromédico, e pela Portaria nº1863/2003 do Ministério da Saúde, deve existir uma capacitação contínua para os profissionais que lidam com os serviços de urgência tanto na modalidade fixa quanto na modalidade móvel, podendo ser terrestre ou aéreo (MINISTÉRIO DA SAÚDE, 2003).

Ao se falar em Gestão do Conhecimento, muitas vezes estaremos correlacionando com um tipo de conhecimento que está altamente atrelado ao conhecimento tácito (BARBOSA, 2008). Takeuchi e Nonaka (2009) referenciam que, ao se falar sobre conhecimento, é importante separar o conhecimento explícito do tácito. Esse conhecimento explícito diz respeito a uma transmissão de dados de forma sistemática, podendo ser expressa em palavras, números e sons. Já o conhecimento tácito é o então conhecido "know-how"; os "insights" estão também relacionados a esse conhecimento tácito.

Ao trazer o conceito de Gestão do Conhecimento para a área da saúde, a Organização Pan-americana de Saúde, desde 1960, já referenciava um método no qual não se pode separar a Gestão do Trabalho da Gestão do Conhecimento (RIBEIRO, 2004). Lemos (2012) e Bezerra et al. (2012) corroboram com esse conceito e mencionam que é importante os profissionais da saúde conhecerem o ambiente de trabalho onde será desenvolvido o processo de educação. Para tal, a Gestão do Conhecimento deve ser composta e apoiada por um processo no qual os profissionais recebam uma formação política-pedagógica.

Cecim (2004), ainda ressalta que a educação nos serviços de saúde não pode ser baseada apenas nas listas de necessidades individuais de atuação, mas pautadas nas necessidades centrais e gerais. $O$ autor ainda relata que é necessário 
entrar em tópicos mais subjetivos como a humanização e a integralidade do cuidado. Além disso, o autor referencia que os processos de qualificação do pessoal de saúde deveriam ser estruturados a partir da problematização do seu processo de trabalho, trazendo a realidade das necessidades de saúde das pessoas e das populações.

O cruzamento de temas de capacitação em saúde, gestão do conhecimento a atendimento pré-hospitalar (APH) leva à utilização de protocolos. Tais protocolos orientam os profissionais no sentido de realizar um atendimento com qualidade, organização e padronização de uma assistência segura. Mesmo com os protocolos, é possível realizar, de forma mais individualizada, um atendimento de acordo com a necessidade de cada tipo de indivíduo, que pode possuir um quadro clínico mais delicado ou grave. Tais atualizações serão baseadas por protocolos e pela educação continuada ou educação permanente (BONIN, 2016).

\section{CONSIDERAÇÕES FINAIS}

Quando se fala em modalidades de educação na área da saúde, deve se ter em mente que é fundamental realizar a gestão do conhecimento e a do trabalho de modo que se processem concomitantemente. $O$ resultado dessas ações irá garantir uma melhor prática baseada nas referências técnicas-científicas e evidenciadas nas práticas realizadas nos transportes aeromédicos.

\section{REFERÊNCIAS}

BEZERRA, E.C; SILVA, L.C.S.C; GONÇALO, M.C; MIGUEL, Z.F. Uma análise da qualificação profissional com base na avaliação de desempenho do plano de Cargos, carreiras e remuneração e sua relação com a política de educação permanente da SESAP/RN. In: CONGRESSO CONSAD DE GESTÃO PÚBLICA, 5. , 2012, Brasília. Anais...Brasília: Conselho Nacional de Secretários de Estado da Administração, 2012. [s.p.]

BONIN, Wagner Luiz Melo et al. Estratégia de educação para o apoio aeromédico: um estudo descritivo. 2016.

BRASIL. Conselho Nacional de Saúde. Resolução n 466, de 12 de dezembro de 2012. Aprova normas regulamentadoras de pesquisas envolvendo seres humanos. Brasília: Diário Oficial da União, 2013.

CONSELHO FEDERAL DE ENFERMAGEM. Resolução n260/2001.

Conselho Federal de Medicina. Resolução CFM 1.661/2003-Conselho Federal de Medicina-transporte aeromédico

Gentil, R.C. Aspectos históricos e organizacionais da remoção aeromédica: a 
dinâmica da assistência de enfermagem. Rev Esc Enferm USP 1997

GOMES, Marco Antonio Viana et al. Aspectos históricos do transporte aeromédico e da medicina aeroespacial-revisão. 2013.

HERNÁNDEZ, N.M; OLIVERA ,C.E.R. Transporte aeromédico del paciente crítico. Ver Asoc Med Crit Ter Intensiva 2007; 21(4):200-6.

MINISTÉRIO DA SAÚDE, Portaria nำ1863, de 29 de setembro de 2003.

Ribeiro ECO. Educação permanente em saúde. In: Marins JJN, Rego S, Lampert JB, Araújo JGC, organizadores. Educação médica em transformação: instrumentos para a construção de novas realidades. São Paulo: Hucitec; Associação Brasileira de Educação Médica; 2004. p. 285-303.

TAKEUCHI, Hirotaka; NONAKA, Ikujiro. Gestão do conhecimento. Bookman Editora, 2009. 